\title{
Modified eccentric connectivity polynomial of some graph operations
}

\section{Ghorbani, M. A. Hosseinzadeh, M. V. Diudea and A. R. Ashrafi}

\section{ABSTRACT.}

The modified eccentricity connectivity polynomial of a connected graph $G$ is defined as

$$
\Xi(G ; x)=\sum_{u \in V(G)} d_{G}(u) x^{\varepsilon_{G}^{\prime}(u)}
$$

where $\varepsilon_{G}^{\prime}(u)=\sum_{v \in N_{G}(u)} \varepsilon_{G}(v)$ and $d_{G}(u)$ is the degree of $u$ in $G$. In this paper modified eccentric connectivity polynomial is computed for several classes of composite graphs.

\author{
DEPARTMENT OF MATHEMATICS \\ SHAHID RAJAEE TEACHER TRAINING UNIVERSITY \\ 16785-136 TEHRAN, I. R. IRAN \\ Department of Mathematical Science \\ SHARIF UNIVERSITY OF TECHNOLOGY \\ 11365-9415 TEHRAN, I. R. IRAN \\ BABES-BOLYAI UNIVERSITY \\ FACULTY OF CHEMISTRY AND CHEMICAL ENGINEERING \\ 400028 CLUJ, ROMANIA \\ Department of Mathematics, Statistics AND Computer Science \\ UNIVERSITY OF KASHAN \\ 87317-51167 KASHAN, I. R. IRAN \\ E-mail address: ashrafi@kashanu.ac.ir
}

